\title{
SECTION 722: SAFETY VALVE OF THE EXCESS PROFITS TAX
}

\author{
ThomaAs TarizaU*
}

Designed to serve as the safety valve of the excess profits tax-the taxpayers' escape from the otherwise inflexible yardstick of normal earnings measured by the x936-1939 base period or a stated return on invested capital-Section 722 discloses by its very provisions the essential weaknesses of that tax. The excess profits tax was originally conceived by the Treasury Department as a levy upon all profits in excess of a fair return upon a corporation's invested capital. While an excess profits tax law has been enacted only during periods when this country has been at war, its potentialities have not been limited to the taxation of "war-profits" alone. Its possibilities as a permanent and integral part of our system of taxation were not ignored. However, it is now quite clear that the Treasury has finally abandoned any hope the Congress will make the excess profits tax anything more than a temporary levy, designed to recapture excessive profits traceable to an inflated war economy.

It may be urged with some merit that the tax as now designed does not fully or properly achieve its purposes and that it is neither a good excess profits tax nor a sound war profits tax. A corporation with an inflated capital may be permitted a credit in excess of a normal return on its original investment. Another corporation having had unusually large profits during the base period because of a temporary windfall or a fortunate monopoly, may be allowed to retain much of its income which theoretically falls within the category of war profits. Situations such as these exist only because of the conflict of purpose inherent in the present excess profits tax. If it was intended as an "excess profits" tax, a credit based on invested capital alone should be proper, and a comparison with a period of normal earnings would be immaterial. If the tax is intended to reach "war profits," consideration of the taxpayer's invested capital is not material and the excess above those profits attained in a normal period should be the sole criterion. Since the latter seems to be the sole purpose of the present excess profits law, there would seem to be much justification for the elimination of the invested capital credit, particularly in view of the expanded relief provisions of the Revenue Act of 1942.

*L.B., 1929, Columbia University. Member of the New York State Bar, New York City. Tax Legislative Counsel to the Secretary of the Treasury, I938-I943; Legal Assistant to Undersecretary of the Treasury Roswell Magill, 1937-1938. Editor, Columbia Law Review, I927-I929; contributor to legal periodicals. 
In any event, the law now offers credits, of equal rank and dignity, based on both invested capital and normal earnings. In substance, however, the invested capital serves merely as one of a number of relief provisions accorded to corporations having an inadequate earnings base or to those not in existence during the base years. Section 722 is intended to function in those cases where the use of the invested capital credit and the application of the other relief provisions still leave subject to the excess profits tax an amount of income which cannot fairly be called excess profits. The remedy afforded by Section 722 is an enlargement of the average earnings credit, or in certain cases the creation of one where none had previously existed, in order that an equitable comparison between normal earnings and earnings during an excess profits tax period might be obtained.

Section 722 provides that in any case in which the taxpayer establishes that the excess profits tax, without the benefit of the relief therein provided, would result in an excessive or discriminatory tax, and also establishes what would be a fair and just amount representing normal earnings to be used as a constructive average base period net income for the purpose of an excess profits tax based on a comparison of normal earnings and earnings during an excess profits tax period, the tax shall be determined by using such constructive average base period net income. It is further provided that in determining the basis of such constructive base period net income, no regard shall be had to events or conditions affecting the taxpayer, the industry of which it is a member, or taxpayers generally, occurring or existing after December 3I, I939, with certain specified exceptions which will be referred to later.

Subsection (b) of Section 722 provides that the tax shall be considered excessive and discriminatory, in the case of a taxpayer entitled to use the average earnings method pursuant to Section $7 x_{3}$, if its base period net income is an inadequate standard of normal earnings because of some factor appearing in one or more of its five specified subdivisions which will be considered below.

\section{Subsection $(b)(x)$}

"in one or more taxable years in the base period normal production, output, or operation was interrupted or diminished because of the occurrence, either immediately prior to or during the base period, of events unusual and peculiar in the experience of such taxpayer,"

This subdivision is concerned primarily, as the report of the Senate Finance Committee indicates, with an interruption or diminution of production occasioned by an event of a physical character which is unusual and peculiar in the experience of the taxpayer, i.e., fire, flood, hurricane, strikes, etc.

One of the troublesome questions presented by this subdivision is the interpretation of the phrase "immediately prior ... during the base period" which language we find repeated under Subsection (b) (4). Obviously, it was intended that some flexibility be permitted in applying this clause and that no definite limitation of time be imposed. The legislative purpose may be gathered from the explanation contained in the regulations: that "an event is deemed to occur immediately prior 
to the base period if under normal circumstances the effect of such event would not be fully manifested until a year in the base period and such effect is directly related to such occurrence." Thus it becomes apparent that "immediately prior" does not so much relate to a period of time as it does to the requirement that there be a close causal connection between the prior event and the abnormality experienced some time during the base period years. In contrast to Subsection (b) (4), it is difficult to assume a situation within the purview of this subdivision which would be likely to manifest itself within the base period unless it had occurred within a comparatively short time prior to the commencement of such period. Yet, in theory, the time element is not of itself controlling, and the right to relief is predicated upon the showing of a reduced production directly traceable to such prior event, unusual and peculiar in the taxpayer's experience.

There are few taxpayers for whom the occurrence of an event of the character contemplated by this subdivision would be anything but unusual and peculiar. Yet, there are some corporations whose operations are periodically interrupted or diminished by such circumstances and which have had periods of prosperity despite the regular happening of these events. The regulations cite the example of a logging corporation whose operations are annually interrupted by spring floods occasioned by thaws and rains. Another example may be found in the decision of the Board of Tax Appeals in the case of Delaware Terminal Corporation v. Commissioner. The Board, in its findings of fact in this decision, stated that the barber shop industry in the City of New York was subjected to an annual spring strike. Without commenting upon the correctness of that finding, and assuming for the purpose of illustration that a strike can be deemed to be a regular and normal occurrence in this or any other industry, it can be seen that an interruption of business under those circumstances will not in fact reduce the taxpayer's normal earnings. To permit a reconstruction of the period so affected would increase an otherwise normal period of earnings.

It should be remembered that the reference to the base period normal production which is the subject of interruption or diminution connotes normal production or earnings in the year thus depressed and does not necessitate a comparison with any other period of actual normal earnings. Thus, even though a given taxpayer's normal earnings may be said to be approximately $\$ 50,000$ per annum, if during one of the base years its earnings would have amounted to $\$ 100,000$, had its production not been interrupted by flood, it would be entitled to a reconstruction of its earnings for that year upon the level of $\$ 100,000$. The regulations permit the reconstruction of a base period year on the level of operations which would actually have existed in that year, even though such a level is abnormally high for the year in question.

The measure of relief available under this subdivision is the allowance of an additional amount of income in the base period equivalent to the sum of increased

${ }^{1} 40$ B.T.A. I 80 (1939). 
earnings which the taxpayer would have had if the circumstances causing the interruption or diminution of business had not occurred. In reconstructing the disturbed period, consideration may be given to the taxpayer's production or level of operations in the unaffected portion of the base years. If the entire base period is subnormal, comparison may be made with a previous period of demonstrated normal earnings in the taxpayer's business experience or with a comparable competitor or the industry of which the taxpayer is a member. Under any of these methods of comparison, normal earnings must be determined in accordance with the factors of volume of sales, cost of operations, and other elements entering into the computation of net income, actually existing during the period which is being reconstructed.

\section{Subsection (b)(2)}

"the business of the taxpayer was depressed in the base period because of temporary economic circumstances unusual in the case of such taxpayer or because of the fact that an industry of which such taxpayer was a member was depressed by reason of temporary economic events unusual in the case of such industry,"

Whereas the business-disturbing factor in the preceding subdivision is a physical abnormality, Subsection (b) (2) refers to an economic circumstance, temporary and unusual in character, which depressed the taxpayer's base years or served to depress the taxpayer's entire industry during that period. The requirement that this circumstance be unusual in the taxpayer's experience and temporary in nature limits the application of this subsection to those events which, as the regulations phrase it, have "little perceptible effect upon the long run prospects of a business" and thereby tends to exclude those corporations or industries which are normally, chronically or continually in a state of depressed earnings. In those cases a low earning level during the base period is not actually a subnormal condition. It is a proper standard of comparison for those taxpayers since it is representative of their normal earnings.

It is not possible to circumscribe the meaning of the word "temporary." It is subject to elastic interpretation, governed by the nature of the economic circumstance and the type of business affected rather than by the period of time the occurrence is in existence. The same elapsed time may in one case rightly be considered a temporary factor and in another a chronic condition. Ordinarily an event will be considered temporary if it is not usually encountered by the taxpayer or its industry and will have no permanent effect upon the corporation's future earnings.

The Act does not refer to the period in which the economic circumstance must occur. However, from the illustrations of typical economic circumstances contained in the report of the Senate Finance Committee it would seem that this circumstance may take place either during or before the base period. Thus, in the example there given of an industry engaged in a price war which resulted in a depressed base period for its member corporations, the economic disturbance occurs during the base period. In the case of the manufacturing corporation which conducts its business with a single customer and which, upon losing that customer, must of necessity 
develop a new market, this subdivision should be applicable whether the loss of its customer occurred prior to or during the base period. It is true that the Senate Finance Committee, in citing the latter example, refers to the happening of this event during the base period and the regulations repeat the illustration verbatim. Nevertheless, it could not have been intended to limit the scope of this subdivision in this way. It would be entirely consistent with the purpose of Subsection (b) (2) to grant a taxpayer relief where the temporary economic circumstance occurs some time prior to the base period if the impact of such event is felt during the base period and causes a depressed earning level.

Thus, let us assume the case of a paper manufacturing corporation which had never had a sales department since it commenced business; its entire and substantial output was sold to an unrelated distributing company which in turn disposed of the product among thousands of its smaller customers. Several years prior to the base period the manufacturing corporation and its distributor terminated their sales contract and the manufacturer, being unable to acquire another distributor, was forced to develop its own sales outlet. If in this case the corporation could not normally have developed by 1936 the volume of sales which it had had prior to its parting with the distributing company, and the base years earnings were depressed as a direct result thereof, Section 722 (b) (2) should be clearly applicable. It seems reasonable to allow relief under this subdivision if under normal circumstances the effect of the happening of such prior economic circumstance was not manifested until some time during the base period.

The frequent reference in the law and regulations to the taxpayer's "industry" requires an understanding of the limitations of that word as there employed. The regulations loosely define an industry as comprising "a group of enterprises engaged in producing or marketing the same or similar products or services under analogous conditions which are essentially different from those encountered by other enterprises." It will be seen that the group intended to be embraced within the term is not as large as that under the every-day conception of an industry. For example, the electrical products industry would probably be comprised of several industries, within the meaning of Section 722 , the vacuum cleaner manufacturers, the electrical refrigerators manufacturers, the air-conditioning equipment manufacturers, etc. The fact that some of the larger corporations may manufacture more than one of these products does not alter the situation for they may well be classed as members of more than one industry. Certainly the factors which may materially affect the base period of the air-conditioning industry might have no influence upon the earnings of other classes of manufacturers in the electrical products group.

The method of establishing a constructive base period income under Subsection (b) (2) is similar to that employed under the previous subsection, that is, on the basis of profit factors existing during the base period. However, if the economic circumstance disturbs the prevailing profit factors its effect may be ignored. Thus, 
if the economic circumstance relates to the labor market, causing unusual and excessive pay rates, in reconstructing the cost of operations for the disturbed period, the excessive charges may be eliminated and normal salary schedules substituted. If the economic circumstance depresses the earnings of the taxpayer without affecting the taxpayer's industry, reconstruction of the base period may be effected either on the basis of the level of operations and earnings in other parts of the base period, or by reference to the average level in a prior period of normal earnings, or by comparison with earnings of comparable competitors or the taxpayer's industry as a whole. If the taxpayer's industry has been affected, the reconstructed period may be established either by reference to the taxpayer's earnings experience in normal parts of the base period, by reference to a prior period of moderate earnings, or by comparison with the base period experience of comparable corporations or industries.

\section{Subsection (b) (3)}

"the business of the taxpayer was depressed in the base period by reason of conditions generally prevailing in an industry of which the taxpayer was a member, subjecting such taxpayer to

"(A) a profits cycle differing materially in length and amplitude from the general business cycle, or

"(B) sporadic and intermittent periods of high production and profits, and such periods are inadequately represented in the base period,"

In drafting the Excess Profits Tax of I940 and its relief provisions, Congress made no allowance for the possibility that the base years of 1936-1939 might for some industries be a period of subnormal earnings. The corporate taxpayer employing the average earnings credit could use only the base years selected since no provision was made for a more equitable base period in the case of those classes of taxpayers whose earning experience did not conform with the experience of business in general. The 1942 amendment of Section 722 under Subsection (b) (3) will afford substantial relief for corporations which are members of an industry whose recurring periods of normal profits are at variance with the average business profits cycle and those corporations whose irregular pattern of profits are not adequately represented in the base period years.

Subdivision (A) of Subsection (b) (3) deals with the problem of the variant profit cycle-a type which does not conform with the general business cycle. There are undoubtedly many industries whose earning patterns do not normally and regularly parallel the experience of American business in general. If the profit cycle of one of these industries were to be superimposed upon a cycle representative of general business they would not regularly coincide and, consequently, their years of profits or losses, normal or subnormal earnings, would not occur at the same time. Accordingly, the taxpayers which compose such an industry may, as a result of this variance, have experienced a period of subnormal earnings during the base 
years of 1936 to x939. Their base period earnings, therefore, would be an inadequate standard of normal earnings, an inequity which this section attempts to correct.

The Act requires that the profit cycle of the taxpayer and its industry differ materially "in length and amplitude" from the general business cycle. If these conditions exist there will be a decided variance between the two cycles. However, there are many other conceivable situations, where relief was clearly intended under this subsection, which will not satisfy the test of a difference in both length and amplitude. Nevertheless, the taxpayer in each of these cases may not have had average normal earnings during the base period years solely because it was in the trough of its earning cycle during all or part of that period. The fact that either the length or the amplitude of the taxpayer's cycle happens to conform with the general business cycle should be of little consequence in the determination of its right to relief.

The Treasury Department, apparently desiring to avoid the confusion likely to result from the strict interpretation of the subsection, has phrased its regulation so as to nullify the necessity for proof of a variance in length and amplitude. The regulations state that a profit cycle shall be deemed to differ in length and amplitude if the taxpayer's period of normal profits has not occurred during the base period but at some prior time entirely or partly without the base period and, further, that it is not necessary that the crests and troughs vary from the level of high and low profits of the general business cycle. Therefore, despite the statute's express requisite, if the base period is not a time of normal earnings because of a profit cycle which does not conform with the normal pattern of industry in general, and even though the length and amplitude of the cycle does not vary from that of general business, Subsection (b) (3) will be considered applicable.

The taxpayer and its industry must be able to show a history of earnings which fluctuated with some regularity in accordance with certain recurring economic causes. That is, to quote the regulation, its business experience must be "susceptible of segregation into a cyclical pattern." This does not mean that the taxpayer and its industry must have had, prior to the base period, an earnings experience which has gone through a series of complete cycles, which, within the common meaning of the word "cycle," recurred and repeated itself at regular intervals. Such a construction would preclude many taxpayers, otherwise qualified, whose business experience, or that of its industry, is of relatively short duration or those whose cycles require a great many years for completion. If the conditions which cause the fluctuation of earnings necessary for a cycle pattern have previously prevailed in the history of such an industry and may be expected under normal conditions to result in periodic and substantial changes in the level of earnings, the earnings experience is cyclical in form. It would seem entirely possible to prove a corporation's earnings susceptible of cyclical segregation even though it has not yet gone through the complete revolution of a single cycle. 
There are certain industries whose earning cycles vary from that of industry in general because their periods of normal earnings primarily depend upon years of general business prosperity. Such industries, as exemplified by the manufacturers and retailers of various luxury items, exhibit a tendency to lag behind the general business cycle. Such items are not widely purchased until the consuming public feels able to afford them. The wage earner is not conscious of prosperity until better business conditions permit his employer to increase his salary-the stockholder, when corporate earnings warrant the declaration of increased dividends. Accordingly, these industries do not attain a period of normal earnings until the general business cycle is well advanced, and may be expected to continue having normal earnings after the general business cycle has begun its decline from normal. Under such circumstances, these industries will have part of their period of normal earnings within the base period years and part without, a situation indicative of a variant profit cycle.

A taxpayer does not qualify as a variant cycle case merely because its industry's and its own level of earnings were below the average earnings of industry in general during the base period years. The circumstances which caused its depressed earnings must be shown to be ordinary and usual for the taxpayer's industry in the sense that such factors have either previously appeared, or may be expected to appear, with some regularity in the industry's experience. If the circumstance responsible for the subnormal base period earnings is unusual and extraordinary in character, it would not tend to recur, but as an unusual economic circumstance it may provide a basis for relief under Subsection (b) (2).

The relief which is permissible under Subdivision (A) may be based upon comparisons with one or more prior periods of not less than three years duration in the taxpayer's experience, or in the experience of the taxpayer's industry, which can be shown to have been periods of normal earnings. The regulations suggest that if no such prior comparable periods are available, comparisons may be made with other taxpayers or industries of comparable financial size and type of product, for which the base period has been a period of normal earnings. It may be noted here that the Treasury's concession that a corporation otherwise entitled to relief under Section $72(\mathrm{~b})(3)(\mathrm{A})$, may not have a prior comparative period of normal earnings would seem to lend much weight to the position heretofore taken that a taxpayer may be entitled to relief as a cycle case even though the taxpayer and its industry had not experienced a complete profit cycle.

The major restriction upon the choice of a prior period of normal earnings which is to serve as basis of comparison is that such a period must bear the same relationship to the profits cycle of the taxpayer and its industry as the base period bears to the general business cycle. Stated in another way, since the base period years of 1936 to 1939, established as a period of normal earnings, had in fact a higher earnings level than the average of prior earnings of business in general, the 
comparative period selected by the taxpayer may show the same proportionate increase over the profit cycle of the taxpayer and its industry, but may not exceed it. Thus, if it may be concluded that the base period earnings level is approximately $20 \%$ higher than the average earnings of the general business cycle, the selected "normal" period may not be more than $20 \%$ better than the taxpayer's and its industry's average earning experience.

Subdivision (B; of Subsection (b) (3) covers the situation of sporadic and intermittent peaks of profits which are inadequately represented in the base period. In a sense this is an unusual type of cycle, a class of irregular and variable cycle in which the sporadic and unusually high profit years are caused by circumstances beyond the control of the taxpayer. However, the Treasury does not consider this a true cycle case because of its irregular and unpredictable pattern. In fact, the regulations indicate that this subdivision is distinguishable from (A) in that the taxpayer's earnings experience hereunder is not capable of cyclical segregation.

These years of unusually high production and earnings, although uncertain and unpredictable as to their time of occurrence, are, on the average, part of the normal earnings pattern of this type of corporation. The level of earnings necessary to sustain this taxpayer is predicated upon the high profits recurring in these peak years. If such years did not appear from time to time, its otherwise low rate of profits would make such business unprofitable. Therefore, if during the 1936 to 1939 period this taxpayer did not have one of its peak years, the base period would not on the average reflect normal earnings. Obviously, in order to sustain a claim hereunder, it must be shown that the base years were in fact a period of subnormal earnings. Otherwise, the base period would be an adequate standard of comparison even though the peak profit years are not represented therein. It is not sufficient for a taxpayer to show that upon certain prior occasions its earnings reached unusually high levels. It is only where these tecurring peak years are entirely normal in the experience of the taxpayer and its industry and are the result of definite factors peculiar to that industry that this subdivision is intended to apply.

Since Subsection (3) refers generally to a depressed base period resulting from conditions prevailing in the taxpayer's industry, it is a requisite under (3) (B) that the entire industry be subject to such irregular pattern of earnings. While it was undoubtedly intended to afford relief to this type of corporation even if its earnings experience does not conform to that of its industry, such a taxpayer would probably have to qualify under Subsection (b) (5).

The report of the Senate Finance Committee suggests the fruit canning industry as a possible example of the situation governed by this subdivision. In that industry profits are dependent upon the fortuitous combination of a good crop and a firm market. Other canning industries, such as farm produce, salmon and tuna fish packing, may well have earning records typical of this situation. Certain apparel 
industries, with products for which the demand is subject to the unpredictable dictates of fashion, are also possible examples.

The method of reconstructing the base period is in most respects similar to that under (3) (A). The taxpayer may reconstruct upon the basis of a prior period which is demonstrated to be more representative of normal earnings. Or, in a proper case, normal earnings may be determined by employing the average of the taxpayer's earnings for its entire business experience prior to January I, 1940. The latter method offers the simplest and most precise formula for reconstructing a base period to be found in the regulations governing this section. The regulations fail to disclose under what circumstances a taxpayer may properly employ this method. It must be assumed that the taxpayer's right to use it will depend upon whether the average of its past earnings are a reasonable reflection of normal earnings.

\section{Subsectron (b) (4)}

"the taxpayer, either during or immediately prior to the base period, commenced business or changed the character of the business and the average base period net income does not reflect the normal operation for the entire base period of the business. If the business of the taxpayer did not reach, by the end of the base period, the earning level which it would have reached if the taxpayer had commenced business or made the change in the character of the business two years before it did so, it shall be deemed to have commenced the business or made the change at such earlier time. For the purposes of this subparagraph, the term "change in the character of the business" includes a change in the operation or management of the business, a difference in the products or services furnished, a difference in the capacity for production or operation, a difference in the ratio of nonborrowed capital to total capital, and the acquisition before January $\mathrm{x}$, 1940 , of all or part of the assets of a competitor, with the result that the competition of such competitor was eliminated or diminished. Any change in the capacity for production or operation of the business consummated during any taxable year ending after December 3x, 1939, as a result of a course of action to which the taxpayer was committed prior to January 1,1940 , or any acquisition before May 3I, I94I, from a competitor engaged in the dissemination of information through the public press, of substantially all the assets of such competitor employed in such business with the result that competition between the taxpayer and the competitor existing before January I, 1940, was eliminated, shall be deemed to be a change on December 31, 1939, in the character of the business."

Measured by the number of taxpayers whose applications for relief are likely to be governed by it, this is probably the most important subsection of Section 722 . The great mass of corporations first coming into existence during the years $193^{6}$ to 1939 and the even greater group of taxpayers which during that period in some way changed the character of their operations or the nature of their products, fall within the purview of this subsection. If, because of such commencement or change in the character of its business during or immediately prior to the base period, a taxpayer's net income for those years is an inadequate reflection of its normal operations for the entire period, an adjustment or theoretical reconstruction of its base years will be permitted in accordance with the concept of normal operations. 
The subsection, elaborating upon its intended scope, sets forth these situations which will be considered to have been a change in the character of business: (I) a change in operations or management, (2) a difference in products or services, (3) an increase in the capacity of production, (4) a difference in the ratio of non-borrowed capital to total capital and, (5) the acquisition before January I, I940 of the assets of a competitor, thus reducing or eliminating competition. The first classification has been added to the law by the I 942 amendment to the section, the others are restatements of previously existing bases for relief. Not every change in management or in the method of operations, whether substantial or otherwise, will of itself satisfy the requirements of the section. Where, however, such a change does result in a substantial increase in the corporation's earnings, whether by reason of a more aggressive management or sales force, an increase in its expenditures for advertising or a change in its major advertising medium, an increase in the efficiency of its manufacturing operations resulting in decreased costs, a radical improvement in the quality of its existing products, or because of any other factor traceable to such change, the taxpayer is entitled to have the effect of such a change extended to its operations in the entire base period.

The requirement that the commencement of business or change in its character occur during or immediately prior to the base period is subject to the same explanation as that offered above under Subdivision (b) (I). If the effect of such a change manifests itself at some time during the base period, it will be deemed to have taken place immediately prior thereto without regard to the length of the intervening period. It may normally be expected that some time will elapse between the inauguration of a new business or the occurrence of some change in character before the attainment of normal operations or earnings. The time-lag or delay in reaching a normal level may in many instances under this subsection be substantial. Nevertheless, this circumstance will not serve to disqualify a taxpayer if its level of normal earnings could not ordinarily have been attained prior to the base period.

Express provision is made for the corporation which did not reach by the end of the base period the earning level it would have reached had it commenced business or had a change in character two years prior to the actual date thereof. In those cases the commencement or change is deemed to have taken place two years prior to the date of the occurrence. This provision is intended to apply to corporations which, as a result of such commencement or change, were in the process of growth or expansion during all or part of the base period. The Senate Finance Committee viewed it as an opportunity afforded growing corporations to establish within a period of normal earnings a larger earning capacity attributable to the theoretical two year earlier commencement or change. To qualify as a "growth" corporation its record of earnings must indicate a steady rate of growth during the base period and, if in actual existence at that time, immediately prior to the base years. How- 
ever, in the determination of growth or expansion, no consideration may be given to events occurring or existing after December 3 r, 1939 .

The extent of the relief available to taxpayers in a period of growth during the base years is measured in one of two ways. If the taxpayer's business actually reached the level of earnings by the end of the base period which it would have reached had its commencement or change in the character of business occurred two years prior to the date thereof, its base years may be reconstructed upon the level of operations actually attained. In this case the taxpayer's earning level would not be increased as a result of a theoretical two year "pushback." The level attained by the end of the base period will be considered its normal earnings capacity and no regard will be had for any increase in that level subsequent to its base years. This taxpayer's entire base period, notwithstanding that it was not in existence throughout the base period, may be reconstructed upon the basis of the character, nature and size of the business actually developed prior to January $\mathrm{I}$, I940. The regulations suggest that this does not necessarily mean that the highest level of earnings actually or constructively attained should be ascribed to the entire base period. The earnings of a business would naturally tend to fluctuate to some extent during each of the base period years in accordance with the variations in sales, production costs and other factors entering into the determination of profits in each of those years.

If, on the other hand, the taxpayer's business did not reach by the end of the base period the level of earnings it would have reached had the commencement or change in character of business occurred two years prior to the actual date thereof, its base years may be reconstructed upon the hypothetical level of earnings which would have been attained by it if that event had in fact occurred two years earlier. The regulations state that in such a case the constructive average base period net income may depend upon reconstructed, as opposed to actual, production, costs, demand, sales and selling prices. Thus, in the determination of constructive normal earnings for the base years, consideration may be given to estimates of these factors based upon the earlier commencement and to comparisons with similar taxpayers or the industry of which the taxpayer is a member. Of necessity, the base period income thus reconstructed must depend in some degree upon speculation and conjecture.

It should be noted, however, that the constructive average base period net income which is used in computing the tax in the first and second excess profits tax taxable year must be based upon the actual earning capacity which the taxpayer could reasonably have expected to reach during those two years. Otherwise the constructive amount of normal earnings based upon a two year push-back may be founded upon a productive capacity which accedes the capacity attainable in those excess profits tax taxable years and would thereby constitute an improper standard of normal earnings for those years. In effect, therefore, the reconstruction of normal earnings used in determining the excess profits tax in any year must not be based upon a capacity greater than that which would have been available in any such taxable year. 
Is the taxpayer which commenced its business, or had a change in the character of its business, during or immediately prior to the base period, and whose base period net income does not adequately reflect normal operations for the entire period, limited in the reconstruction of its base period net income by the earning level which it would have attained had it commenced business or had its change in character two years prior to the actual event thereof?

It was the intention of Congress to permit a taxpayer in any case where it could be demonstrated that its excess profits tax was discriminatory or excessive within the meaning of Section 722 (b), to establish what would be a fair and just amount representing its normal earnings during the base period years and to permit the use of a constructive average base period net income predicated upon such an amount. Any interpretation of the law which prevents a taxpayer from proving the amount of its normal base period earnings or to limit the amount thereof to be assigned to its constructive base period net income must be considered erroneous because it is contrary to that intention.

The first sentence of Subsection (b) (4) relates to the situation where base period net income, because of the commencement or change in character of the business, does not reflect normal operations. The second sentence refers only to growing corporations which did not reach the earning level they would have reached had such events occurred two years earlier. These sentences do not by any means deal with the same problems. They might properly have been made separate subdivisions of $722(\mathrm{~b})$.

For example, take the case of a corporation engaged in the business of growing hemp, which commenced operations in 1936 . Its first planting is made in that year followed by other plantings in succeeding years. Since hemp takes seven years to mature, this taxpayer could not be expected to have any earnings until I943. Here the taxpayer did not reach a level of normal operations and fits precisely within the first sentence of Subsection (b) (4). However, if its only measure of relief is to be based upon a reconstruction of the base period net income based upon a two year prior commencement of its operations, no relief is in fact available to it. This taxpayer has not attained any earnings level at all during the base period and was not then in the process of growth. Therefore, even with the two-year push-back it would not attain any level of earnings, normal or otherwise.

Unfortunately, the regulations governing Subsection (b) (4) do not provide illustrations of the methods of establishing normal earnings for cases other than those in the class of growing corporations. Nor, for that matter, is any reference made therein to corporations eligible for relief under this subdivision which do not fall into that category. It must be presumed that this was an oversight rather than a determination to deny a fair and just amount representing normal earnings to those taxpayers whose base period net income does not reflect normal operations of the business. 
A change in the capacity of production or operation which was consummated subsequent to the base period years, if such change is the result of a course of action to which a taxpayer was committed prior to January $I$, I940, is deemed to be a change in the character of business occurring on December 3r, I939. Competent evidence of any form may be offered as proof of the taxpayer's commitment to a course of action. The fact may be evidenced by a contract, the expenditure of money, the placement of an order, or any other change in position indicative of the taxpayer's intention to make such a change. However, since the change in the character of business attributable to December 3I, I939 will actually have been consummated after that date, the results or effects of such a change may not be reflected at all in the business of the taxpayer during an excess profits tax taxable year prior to the utilization of such change, or only partially reflected in a year in which the change has been partly utilized in the business.

Thus, if a taxpayer makes a commitment in 1939 for an increase in the capacity of its plant and the work involved is not completed until June $\mathrm{I}, \mathrm{I} 94 \mathrm{r}$, its constructive average base period net income used in determining its excess profits tax for r940 may not reflect the increased capacity; for the taxable year 194r, one-half of such increased capacity may be considered in establishing constructive net income. If in this example the increased capacity had been partially completed in 1940 and that part had been placed in operation and utilized in the taxpayer's business, the increased production may be reflected in the determination of normal earnings to the extent thus utilized.

Generally the constructive average base period net income is determined by reference to a level of full normal capacity as of December 3r, 1939, which, pursuant to the provisions of this subdivision, is deemed to include the increased capacity for which the taxpayer was committed prior to that date. For any taxable year subsequent to a year in which such change has been completed and utilized in the taxpayer's business, the constructive average base period net income may reflect the entire increase in capacity, regardless of whether the increased capacity was actually utilized in the business of that year.

While it is a basic principle of Section 722 that no regard may be had of events or conditions affecting the taxpayer, comparable taxpayers, or the industry of which it is a member, occurring after December 3I, 1939 as an indication of normal earnings, the force of that rule is relaxed in the case of taxpayers subject to the commitments here discussed. Although actual earnings after that date may not be offered as criteria of normal earnings, the extent to which the change in capacity after December 3r, I939 has increased the taxpayer's previous capacity of production may be taken into account. Accordingly, in establishing constructive base period net income, normal earnings may be indicated by use of the ratio between earnings in the taxable year attributable solely to the increased facilities and earnings from capacity previously available, the percentage of increased earnings thus determined 
may be applied to the base year earnings as an indication of the level which would have been normal for that period.

It is not intended that a taxpayer have the benefit of a duplication of an excess profits credit afforded by some other section of the law. Thus, if the amount of money disbursed in an excess profits tax taxable year for the acquisition of such increased capacity constitutes a capital addition, for which the taxpayer is granted a credit under Section $7 \mathrm{x}_{3}(\mathrm{a})(\mathrm{I})$ (B) equivalent to $8 \%$ of such addition, the constructive average base period net income attributable to the changed capacity must be reduced in that taxable year by the amount of the $8 \%$ credit.

\section{Subsection (b)(5)}

"of any other factor affecting the taxpayer's business which may reasonably be considered as resulting in an inadequate standard of normal earnings during the base period and the application of this section to the taxpayer would not be inconsistent with the principles underlying the provisions of this subsection, and with the conditions and limitations enumerated therein."

It would not have been feasible to have enumerated in the Internal Revenue Code every variety of situation which would give rise to an excessive and discriminatory tax. Subsection (b) (5), commonly referred to as the "catch-all" provision, was the practical solution. Its purpose is to grant relief to taxpayers whose base period years are depressed because of any other factor not specifically enumerated therein where such a claim would not be inconsistent with the basic principles underlying Section 722.

The Senate Finance Committee report offers, as an illustration of this subsection, the case of a whiskey manufacturer commencing business in 1935 whose entire stock was in the process of being aged during the base period. Having no salable product available during the base years, its earnings could be expected to be subnormal, if not nonexistent, during those years. The similarity of this illustration to that of the hemp growing corporation previously discussed under Subsection (b) (4) is immediately apparent. The only distinguishing factor is that the hemp growing corporation commenced business during the base period while the whiskey corporation was organized in 1935, an immaterial distinction inasmuch as the commencement in 1935 clearly falls within the definition of "immediately prior" to the base period.

The extent of the Committee's confusion in its use of this example may be gauged by the fact that the same example was employed by it as illustrative of a typical (b) (4) situation in its "summary of principal changes" preceding the text of its report. Its report further confuses the situation by suggesting that such a case might qualify under (b) (2) were it not for the fact that "it might be said that the business was not depressed during the base period since it was operating at full manufacturing capacity." No explanation is given of why the Senate Finance Com- 
mittee did not consider that this case meets all the requirements of Subdivision (b) (4).

The regulations relating to Subsection (b) (5) do not suggest the method of determining a constructive base period net income for taxpayers eligible thereunder. The reason for this omission is understandable. It may be expected that most cases which qualify under (b) (5) will, from a factual standpoint, be similar in many respects to situations governed by one of the first four subsections. They will find themselves within the catch-all provision because, while entitled to relief in principle, they do not satisfy the conditions of any one of the previous subsections. It is undoubtedly the intention of the Treasury Department, although unexpressed, that the general method of establishing normal earnings as suggested for the subsection nearest in principle to the case qualifying under (b) (5) shall be considered applicable.

\section{SECTION 722(c)}

Corporations which have not been in actual or constructive existence during any part of the base period are not entitled to use an excess profits credit based upon average earnings pursuant to Section $7 \times 3$. Generally, the credit available to them is based upon a stated percentage of their invested capital. Heretofore such newly incorporated businesses were not granted any form of relief even where the insuffciency of the credit so computed resulted in an excess profits tax which was patently excessive and discriminatory.

Section $722(c)$ is designed to offer relief to such corporation, upon proof of the excessiveness of its tax, and permits the use of an excess profits credit based on income. The excess profits tax, computed without regard to this section, will be deemed excessive and discriminatory if the invested capital credit of such taxpayers is an inadequate standard of determining excess profits because:

(I) the business of the taxpayer is of a class in which intangible assets not includible in invested capital under Section $7 \times 8$ make important contributions to income,

(2) the business of the taxpayer is of a class in which capital is not an important incomeproducing factor, or

(3) the invested capital of the taxpayer is abnormally low.

The first clause of Section 722 (c) may be illustrated by a corporation, organized in I940, whose level of earnings is dependent upon the number of contacts it makes in the industry which it services or supplies, rather than upon its small invested capital. Since its most important asset, the good will which it has established in the trade, is not reflected in its invested capital, the corporation is entitled to relief. The second class of taxpayers is the group in which invested capital does not play a vital role in producing income. The regulations suggest the example of a corporation doing business as fashion consultants which is not able to qualify as a personal service corporation under Section 725 because it has a large staff of technical and professional assistants. The final clause relates to a taxpayer engaged in a business 
in which invested capital is normally substantial, but where, because of some factor peculiar in its case, its invested capital is abnormally low. A corporation which leases all of its manufacturing facilities, or sub-contracts the major part of its production, may be a fair example of this situation. If its invested capital is established to be abnormally low in relation to the size of its business, it should be able to qualify under Section $722(c)$.

The inadequacy of a credit based upon invested capital in such cases is obvious. However, the fundamental difficulty of establishing a reasonable substitute basis may be considerable. The law provides that taxpayers qualifying hereunder shall be entitled to use an excess profits credit based on income, using a constructive average base period net income determined in the same manner as that provided for taxpayers eligible under $722(\mathrm{~b})$. These taxpayers have not had any earning experience in the base period years and consideration may not be given to the actual level of earnings attained thereafter. Therefore, hypothetical normal earnings for the base period may only be approximated through the use of comparatives.

Initially, the taxpayer is required to offer proof of the essential similarity of the competitors which it seeks to use as comparatives. For this purpose the requirement that no regard may be had to events or conditions affecting the taxpayer occurring after December 3I, r939 must of necessity be relaxed. The similarity may be established by a comparison of the taxpayer's profits and sales in the period subsequent to its commencement of operations with those of such comparable concerns during the same period. The existing relationship between the character and experience of each of their managements, the nature of the competition offered and any other factor material to the determination of normal earnings must be considered. The taxpayer may then reconstruct its base period net income upon the basis of the established relationship with such competitor's sales and earnings during the base years. The regulations suggest, however, that it may not be necessary to reconstruct each year in the $193^{6-1939}$ base period and that the average of such reconstructed normal earnings may be used.

\section{Relationship of Other Relief Sections to Section 722}

It should be noted that the relief provisions of Section 722 do not in all cases preclude simultaneous resort to other relief sections of the law. The regulations state that a taxpayer may not as a matter of right, in determining its constructive average base period net income under Section 722, apply some other section, such as $7 \mathrm{I}_{3}(\mathrm{e})(\mathrm{I})$ or $7 \mathrm{I}_{3}(\mathrm{f})$. However, it asserts that such a procedure may be permissible in a proper case to the extent that such sections are not inconsistent with Section 722. While the regulations do not reveal what would constitute a proper case, it is reasonable to conclude that the practice will be considered proper where the combined application of the two sections will not result in a duplication of benefits. 
Consider the case of a New England corporation which had an operating deficit in 1936 and which, in common with many other corporations in that locality, had its plant inundated by the hurricane and flood which struck that area in 1938 . Its application for relief under Section $722(\mathrm{~b})(\mathrm{I})$ may serve to eliminate the abnormal effect of the 1938 flood and return that year to normal. Nevertheless, it would be grossly inequitable to deny such a taxpayer the right to exclude the 1936 deficit from its computation pursuant to Section $7 \mathrm{I}_{3}$ and thereby place the taxpayer at a tax disadvantage with relation to its competitors. Similarly, if any year, other than the year of abnormality adjusted under Section 722 , is less than $75 \%$ of the average of the other three years, it would appear proper to permit the use of Section $7 \mathrm{r} 3(\mathrm{e})(\mathrm{r})$ in conjunction with Section 722 .

However, where a corporation has established in accordance with the provision of one of the subsections of Section 722 that its entire base period is depressed, that section provides for the reconstruction of the income of each of those years upon the level of normal earnings. To permit such constructive earnings to be augmented by the formulae offered in Section $77_{3}(e)$ and (f) would be clearly inconsistent with the principles of Section 722 , since the resulting credit will be based upon an amount in excess of normal earnings.

The same view may be taken of the question of whether a taxpayer's constructive base period net income may be determined by the application of more than one of the subsections of Section 722. A corporation may have been affected by a physical disturbance in 1936 and depressed by reason of some economic factor in 1938 . There does not seem to be any reason why Subsections (b) (I) and (b) (2) may not both be relied upon to establish normal earnings for the base period years. On the other hand, once a base year or the entire base period has been reconstructed to reflect normal earnings in accordance with the provisions of the regulations governing one subsection, a taxpayer may not then rely upon another subsection to increase that figure to an amount in excess of normal earnings.

\section{ConCLUSTON}

The liberalization of Section 722 by the Revenue Act of 1942 extends beyond the mere increase in the classes of taxpayers eligible for relief. The elimination of the prerequisite that an application under the section result in a tax saving of at least 10\% will open the door for a large number of taxpayers, otherwise qualified, which have heretofore been denied the benefits of Section 722 . The deletion of that provision thus permits the filing of an application under the section for a year in which a taxpayer has had no excess profits tax to pay. A resulting increase in the unused excess profits credit will present the taxpayer with a larger credit carry-over or carry-back with which to reduce the tax liability for a prior or subsequent taxable year. It should be pointed out that the application need not be filed until the year in which the credit is to be applied. 
Despite the substantial relief that is afforded by Section 722 , there still remain cases of actual hardship under the excess profits tax, which find no help in that section. The problem of growing corporations has been only partially met by the two-year growth provision. There will be many corporations whose natural growth would equitably entitle them to a much higher credit than is afforded by the law. The problem of the corporations formed since the base period is not satisfactorily solved by Section 722. Section 722(c) affords relief only to very. few types of newly formed corporations, and the great body of new business is limited to the invested capital credit. A new and growing business is placed under a severe handicap when its earnings are limited to a fixed percentage of invested capital while its competitors may have a much higher credit, because of the benefits of base period experience. This treatment of new corporations would tend to foster a monopoly and stifle growth to an extent serious to the national economy, were it not for the fact that the amount of new business now being formed for other-than-war purposes is negligible.

Despite these deficiencies, Section 722 takes care of the more serious inequities that would otherwise arise under the excess profits tax. Its broad scope enables the Treasury and the Tax Court to so mitigate the hard and fast rules for determining the excess profits tax credit that in most instances no drastic hardship is caused by the confiscatory $90 \%$ excess profits tax rate. The extent to which the section will be effective in giving relief will depend, of course, upon its administration. Efficient administration will furthermore depend to a great extent upon the reasonableness and self-control of the taxpayers. The Bureau of Internal Revenue, already hard-pressed by additional duties and responsibilities thrust upon it by the program of war taxation, will be greatly hampered in its application of the section if it is swamped by a great volume of unreasonable and unfounded claims. Very often, the result of an avalanche of unreasonable petitions for relief is the creation of an unfavorable attitude toward even reasonable and fair claims. On the other hand, the Bureau of Internal Revenue, confronted as it is with a section which calls for the exercise of an unusual amount of judgment and discretion, must be prepared to be more bold and vigorous than administrative agencies usually are. 